\title{
Towards an Art of Adaptation: Film and the New Criticism-as-Creation
}

\author{
Lindiwe Dovey
}

Many filmmakers have chosen what they would call a "faithful" approach to adaptation, in which the plot and characters are extracted and utilized as the basis of the action represented in the film. The resulting adaptations have catapulted classic narratives (usually novels or plays) into a more lucrative medium, thereby exploiting the text as a template or stencil and reducing the adapter to a mere copier of plot. What the adapter borrows is essentially the narrative, which, as Seymour Chatman points out, lends itself most easily to such borrowing. Chatman writes:

One of the most important observations to come out of narratology is that narrative itself is a deep structure quite independent of its medium. In other words, narrative is basically a kind of text organization, and that organization, that schema, needs to be actualized .... A salient property of narrative is double time structuring. That is, all narratives, in whatever medium, combine the time sequence of plot events, the time of the histoire ("story-time") with the time of the presentation of those events in the text, which we call "discourse-time." What is fundamental to narrative, regardless of medium, is that these two time orders are independent... Narratologists immediately observed an important consequence of this property of narrative texts, namely, the translatability of a given narrative from one medium to another. (435-436)

Lindiwe Dovey is currently pursuing a Ph.D. in African literature and film at Cambridge University. Her work has appeared in such journals as Camera. Inprint, and The Harvard Advocate. She has made two short films and is presently working on a documentary about film adaptation. She is also an alumna of the Salzburg Seminar "From Page to Screen" and was one of the organizers of the Cambridge African Film Festival in May 2002. 
It is precisely the ease of this transition from one medium to another that presents a problem: if adaptation is to acquire the status of "art," it should not be easy. Christian Metz seems to view narrative as the greatest threat to one of the cinema's most important distinguishing features: its lack of a rule-based grammatical system. Unlike the fixed grammatical system which is required in order to make meaning in writing, film's relatively fluid system allows for the development of personal grammars on the part of filmmakers, which emancipates them from inevitably speaking through pre-established codes. Metz suggests that narrative's property of easy translatability undermines this liberating feature of film:

\begin{abstract}
Many people, misled by a kind of reverse anticipation, have antedated the language system; they believed they could understand [a] film because of its syntax, whereas one understands the syntax because one has understood, and only because one has understood, the film. The inherent intelligibility of a dissolve or a double exposure cannot clarify the plot of a film unless the spectator has already seen other films in which dissolves and double exposures were used intelligibly. On the other hand, the narrative force of a plot, which will always be understood only too well-since it communicates with us in images of the world and of ourselves-will automatically lead us to understand the double exposure and the dissolve. (41)
\end{abstract}

Before examining Metz's position on narrative, it is necessary to clarify his assertion that the grammatical systems of literature and film are at odds. Metz refutes earlier structuralist arguments that the film shot is equivalent to a word by pointing out that "the shot [the smallest filmic unit] . . . is closer . . . to a sentence [or paragraph] than to a word. An image shows a man walking down a street: It is equivalent to the sentence 'A man is walking down the street' ... [not] to the word 'man,' or the word 'walk,' or the word 'street"' (67). If shots are equivalent at least to sentences, sometimes even to paragraphs, and if montage is a structuring principle to be determined by the editor, then film certainly has no pre-determined grammar. ${ }^{1}$ Metz intimates, however, that a fixed cinematic grammatical system is in the process of being developed as more and more films are being made and seen. Principles of filming and editing are being taught in film classes as a kind of functional grammar. These, however, are conventions, not rules.

It is narrative that introduces rules-and this is the reason Metz sees the "narrative force of plot" as the greatest threat to personal cinematic systems. It is the plot, Metz says, which allows for the automatic understanding of visual techniques such as the double exposure and the dissolve. Yet Metz's use of the word "understanding" implies that the construction of narrative lies just as much in the reception of the film as in its making. Readers and spectators are implicated along with creators in the problem of narrative construction. This suggests that an alternative approach to the use of narrative in adaptations could avoid mere utilitarian borrowing of story lines and could encourage the viewer to look for more than just narrative significance in the visual elements of the film - that is, to see the images as carrying a complex range of significations, rather than as subordinate handmaidens of plot. This approach would deal with narrative in creative ways-following the 
example of Mickey Madoda Dube who, in his adaptation Nagstappie, transforms the ending of fellow South African Alex La Guma's A Walk in the Night and shifts the novel from an anti-apartheid to a post-apartheid work. Similarly, Dani Kouyatés Keita is creative in its transposition of the Malian oral tale, the Sundjata Epic, into a late-twentieth century context. Such adaptations provided me with models for my own film adaptation, Perfect Darkness, which reevaluates Olive Schreiner's novel, The Story of an African Farm, set in colonial times, through the lens of postcolonialism. As will become evident in this paper, I have drawn significantly on my practical experience of making Perfect Darkness in order to arrive at the taxonomic categories of "pro-creational" and "appropriational." In such a way, I attempt to stress the importance of avoiding theorizing that is alienated from practical experience, and similarly practice that is alienated from theoretical concerns.

The problem of narrative itself has been addressed by many writers and filmmakers, such as filmmaker Jean-Luc Godard, who in the sixties developed a countercinema in opposition to Hollywood (Wollen). Rather than take a stance in that debate, however, this paper critiques a particular use of narrative on the part of the film adapter, one that involves simply borrowing plot and characters, and which corresponds with a mode of adaptation that I call appropriation. In opposition to this appropriational mode, I distinguish an interpretive mode, although I recognize that separating the full range of adaptations into two neat polar categories is inadequate. These two categories are inevitably and inextricably linked, and aspects of the one mode will always accompany an attempted translation in the other mode. For example, an appropriational film adaptation shares certain properties with interpretive film adaptation (such as the interpretive approach required by casting decisions or how to visualize a particular passage), albeit usually owing to the requirements of transforming a verbal medium into a visual medium. On the other hand, the interpretive film adapter must consider questions of plot amidst methodological concerns (particularly if she is adapting a text with a strongly developed narrative). After all, since narrative is the most easily translatable of a text's traits, it is also the most easily recognizable-if an adaptation strays too far from a text's narrative, it risks losing its claim even to being called an adaptation of that text.

E. H. Gombrich defines the "minimum image" of an art work as being constituted by those elements that allow us to recognize it as a representation, translation, or adaptation of something else (5). Göran Sörbom, too, points us to the necessity of a degree of "subject-matter realism" for recognition of an imitation or adaptation. He writes: "When a portrait is made the qualities of the portrait are decided, to some degree at least, by the actual look of the given model if there is going to be a portrait at all" (24-25). In such a way, Gombrich and Sörbom draw our attention to the necessity of some form of narrative fidelity in film adaptation. While appropriational adaptation is characterized by fidelity to story alone, interpretive adaptation is characterized by fidelity to more than story. Interpretive adaptation involves reading the complex range of meaning-making strategies in the written text and rendering this in the medium of film. In trying to clarify this process, I will explore a range of terms proposed by theorists from various disciplines and periods, and will shape my own theory of and term for interpretive adaptation. I will then explain briefly 
why I classify my own adaptation, Perfect Darkness, as interpretive.

In transferring meanings from one language, medium, or context to another, the term that first comes to mind is translation. Roman Jakobson, working in the field of linguistics, divides translation into three categories: intralingual translation (translation within the same verbal language), interlingual translation (translation from one verbal language to another), and intersemiotic translation or transmutation (translation from a verbal language to a nonverbal language) (429). Interpretive adaptation falls into the third category, which Jakobson describes as the "interpretation of verbal signs by means of nonverbal sign systems" (429). In his appellation for this category, "intersemiotic translation or transmutation," Jakobson uses two tropes interchangeably, thereby opening up rather than refining the boundaries of interpretive adaptation; moreover, he makes no distinction between film and other kinds of "nonverbal sign systems."

Barbara Johnson, from her perspective as literary and cultural theorist, does, however, make translation seem appealing as a trope for interpretive adaptation. She does this through her discussion of the translatory act in relation to issues of fidelity: by embarking on the process of translation, she argues, one discovers that in fact no "original" exists, and thus she requires one to reevaluate the question so often posed in relation to translation: is it faithful? Johnson writes:

In studying the différance of signification. Derrida follows the misfires, losses, and infelicities that prevent any language from being one. Language, in fact, can only exist in the space of its own foreignness to itself . . . . For it is necessary to be faithful to the violent love-hate relation between letter and spirit, which is already a problem of translation within the original text. If the original text is already a translatory battle in which what is being translated is ultimately the very impossibility of translation, then peacemaking gestures such as scrupulous adherence to the signifier are just as unfaithful to the energy of the conflict as the tyranny of the swell-footed signified. The translator must fight just as hard against the desire to be innocent as against what we today consider the guilty desire to master the text's message. (146-147)

Johnson hereby condones infidelity to the "original" (whatever that may bethought or text), but encourages fidelity to the "violent love-hate relation between letter and spirit." In such a way, she encourages one to draw the analogy between the interpretive process which occurs in the filmmaker's translation of text to film and that which occurs in the writer's translation of spirit to text (what Johnson calls a "translatory battle"). This is not to relegate "spirit" to some shadowy, whimsical realm of uninscribable sentiment-it only serves to recognize the infidelity inherent even within the "original." Thus, when a film adapter acts on the belief that she cannot be faithful to the letter of the text, she in fact re-stages the very infidelity that occurred in the production of the "original." Sally Potter, film adapter of Virginia Woolf's Orlando, alludes to this infidelity/fidelity dichotomy: “[T]he deeper I went [into writing the script], the more I realized I would have to be prepared to make changes [infidelity to letter] ... in order to stay true to what I loved in the book [fidelity to spirit]" (ix). Thus, adapters cannot dispense with the notion of fidelity 
altogether; the concern is rather about what it is one should be faithful to-or, which aspects of the text could be said to embody its "spirit."

If "spirit" is seen as the expression of the writer's desire, the expression of the writer's self in oblique and ambiguous ways, then it can surely only be embodied by the text in its entirety - the story and the narration, the characters, the metaphors and symbols and allusions, the genre or genres that have been employed, and the thematic issues which the reader sees as linking all of these. While a novel's "letter" could be said to refer to its narrative alone, "spirit" can be seen as incorporating the novel's "letter" along with its other meaning-making strategies. The adapter interested in a novel's "spirit" - not simply its "letter"- - has to make choices that are similar to those made by the translator. These choices constitute an act of interpretation or criticism, as J. M. Coetzee points out:

[I]t is in the nature of the literary work to present its translator with problems for which the perfect solution is impossible and for which partial solutions constitute critical acts. A literary work is, among other things, a structure in which form has become meaning. When form is disrupted, meaning is also disrupted. Such disruption is inevitable, for there is never enough closeness of fit between languages for formal features of a work to be mapped across from one language to another without shifts of value. Thus the work continually presents its translator with moments of choice. ("Achterberg's 'Ballade van de gasfitter"” 88)

Mapping across from one medium to another similarly requires shifts of value. My film adaptation, Perfect Darkness, is interpretive in this sense, and the way in which it represents certain features - such as the mixing of sub-genres within The Story of an African Farm and its questioning of conventional gender roles-foregrounds this act of interpretation. Kamilla Lee Denman has theorized the process of adaptation in the same way, using the term "performative criticism" and defining it as follows:

The film adaptation is a fictional response to the novel on which it is based. Performative criticism in any mode-oral, visual, theatrical, musical, balletic, or filmic_-provides a multi-faceted fictional response to a work of fiction that is not only an aesthetic production but a work of interpretation with layers that can be sensorily, emotionally, psychologically, and intellectually apprehended. Just as reading a poem or novel aloud, casting, directing, performing, or watching a play, or setting a piece of text to music can reveal hitherto hidden aspects of a literary work, so too, the film adaptation opens issues for analysis that might not be noticed through other methodologies. (iii)

Denman's notion of "performative criticism"- that is, a piece of fiction in any medium that interprets a previous piece of fiction in any medium-challenges the assumption that critical discourse can be conceived in non-fictional, verbal language only. Denman's insights suggest that the cinema is not simply a medium for art or entertainment; it can also be an appropriate medium for critical discourse.

Film adaptation, owing to the opportunity it provides for the interpretation of a pre-existing text, is able to claim the status of "performative criticism," or criticism 
articulated as a fictional response. Moreover, film adaptation disrupts the hierarchical system in which the verbal predominates over the visual, a power imbalance that has only recently been challenged. As Denman points out:

\begin{abstract}
A competitive binary has dominated both critical and lay discussions of adaptation. As film critic, historian, and theorist David Bordwell has pointed out, Roland Barthes's application of semiology to non-linguistic signs implicitly makes language the master system. Even the fact that current academic conventions compel me to write about literature and film affirms this master system. (ii)
\end{abstract}

Film adaptation, rather than lamenting the extent of power granted to language, challenges the notion of a linguistic master system by providing criticism in a performative mode. Moreover, performative criticism avoids some of the pitfalls of conventional critical discourse. The first of these pitfalls has been alluded to by Johnson as "the guilty desire to master the text's message." In this way she alludes to the assumption, usually operative in literary criticism, that the critic can expose the truth of the literary text. This is accompanied by an assumption that criticism itself does not express the critic's own desire-which in turn should be open to interpretation. In the same vein, Coetzee has asked the question: "If the desire of literary criticism is to tell every truth, to unveil whatever is veiled, to expose every secret to sight, why does it not tell its own secrets? Or does it claim to have none?" ("Truth in Autobiography" 3).

Oscar Wilde was perhaps one of the first artist-critics to recognize that criticism is inevitably a creative act, that it is not objective but subjective. Wilde writes:

The critic occupies the same relation to the work of art that he criticizes as the artist does to the visible world of form and color, or the unseen world of passion and of thought .... [Criticism] works with materials, and puts them into a form that is at once new and delightful. What more can one say of poetry? Indeed, I would call criticism a creation within a creation .... [T] he highest criticism really is, the record of one's own soul. It is more fascinating than history, as it is concerned simply with oneself. It is more delightful than philosophy, as its subject is concrete and not abstract, real and not vague. It is the only civilized form of autobiography, as it deals not with the events, but with the thoughts of one's life, not with life's physical accidents of deed or circumstance, but with the spiritual moods and imaginative passions of the mind. (1623)

Writing more than a century ago, Wilde presents us with an argument against conventional criticism and its claim to transparency: critical discourse, he suggests, constructs a self on the part of the writer as much as fiction does. Even in the simple act of choosing a particular passage of a poem on which to comment, a critic is presenting for us an aperture to her personality. Through this choice, the critic reveals what moves her, what attracts her, what resonates within her, and ultimately what inspires her to respond to what she has read.

Since Wilde's metaphor for criticism as a "creation within a creation" refers particularly to verbal criticism, it is necessary to distinguish the critical discourse made available to us by cinematic criticism. I make that distinction here by means of 
a new term that presides over and names the combination of fiction and criticism in interpretive adaptations. The term is "pro-creation," a union of production and creation, as opposed to re-production and re-creation. Pro-creation focuses on the collaboration rather than competition between the text and the adapter; it refers to a dialogue mediated by the screen separating the two media, verbal and visual. It envisions the artist-critic's creative stance as a kind of Kandinskyian two-sided mirror, constantly rotating, with the text on one side, and the filmmaker, the procreative agent, on the other. Or, better yet, as the two-sided mirror displayed at the Boston Science Museum, where two reflections are merged into one image on the mediating screen of a mirror. ${ }^{2}$ In addition it suggests an interface-an amalgam of two faces projected into a new domain-instead of merely a surface. "Pro-creation" thus intimates that interpretive adaptations are comparable to offspring: they contain a gene-ric mixture constituted from both the text and adapter rather than merely being genetically derivative of the original text (as appropriations tend to be). One might argue that "re-production" is synonymous to "pro-creation," but pro-creation seems more appropriate, since it foregrounds the aspects of creative production and does not carry with it the connotations of derivativeness. The definitions in Webster's Encyclopedic Unabridged Dictionary make this distinction clear:

Procreation: 1. The act of begetting or generating (offspring).

2. The act of producing; bringing into being.

Reproduction: 1. The act or process of reproducing.

2. The state of being reproduced.

3. Something made by reproducing an original; copy; duplicate.

4. The natural process among organisms by which new individuals are generated and the species perpetuated.

The hyphenated "pro-creation" indicates that it is a composite of "production" and "creation" rather than simply "procreation." It is significant in this respect that Schreiner uses the idea of gestation and birth-the components of procreationas extended metaphors for the artistic process. In her dedication at the beginning of The Story of an African Farm, Schreiner-under the pseudonym of Ralph Ironcalls her book "this little firstling of my pen" (25). Yet in the novel she unsettles conventional gender roles by presenting, for example, Waldo's sheep-shearing invention and his wood carving each as the result of a nine-month gestation period. In this way she shows her feminist impulse to be inclusive rather than exclusive.

In a similar way, through the term "pro-creation," I mean to avoid creating an essentialist metaphor, which would suggest that only women are capable of giving birth to adaptations. Rather, it emphasizes the regenerative quality of adaptation. Schreiner herself seems to condone the regeneration-or pro-creation-of her text with the following words:

The whole of the story is not written here, but it is suggested. And the attribute of all true art, the highest and the lowest, is this-that it says more than it says, and 
takes you away from itself. It is a little door that opens into an infinite hall where you may find what you please .... We see what we see, but nothing more. (169)

Interestingly, Schreiner's words - in her work of fiction-are almost identical to those of Wilde - in his work of criticism. Wilde writes:

To the critic the work of art is simply a suggestion for a new work of his own, that need not necessarily bear any obvious resemblance to the thing it criticizes. The one characteristic of a beautiful form is that one can put into it whatever one wishes, and see in it whatever one chooses to see; and the Beauty, that gives to creation its universal and aesthetic element, makes the critic a creator in his turn, and whispers of a thousand different things which were not present in the mind of him who carved the statue or painted the panel or graved the gem .... You see, then, how it is that the aesthetic critic rejects these obvious modes of art that have but one message to deliver, and having delivered it become dumb and sterile, and seeks rather for such modes as suggest reverie and mood, and by their imaginative beauty make all interpretations true, and no interpretation final. Some resemblance, no doubt, the creative work of the critic will have to the work that has stirred him to creation, but it will be such resemblance as exists, not between Nature and the mirror that the painter of landscape or figure may be supposed to hold up to her, but between Nature and the work of the decorative artist. (16261627)

Working in the twenty-first century, with the wealth of insights provided by the theorists of the twentieth century, one would perhaps not want to go so far as to claim that the critic or filmmaker can find whatever she pleases or see whatever she wishes: one has to recognize that the act of interpretation is circumscribed by the discourses currently in circulation. Schreiner and Wilde nevertheless seem to anticipate the way in which poststructuralism questions the notion of origins (as Johnson does above) and sees meaning as continuously deferred and always dependent upon further acts of interpretation.

This continuous deferral of meaning is also characteristic of allegory, as it has been defined by Paul de Man. De Man points out that the meaning of an allegorical sign consists "only in the repetition ... of a previous sign with which it can never coincide" and that it "exists entirely within an ideal time that is never here and now but always a past or an endless future" ("The Rhetoric of Temporality" 190-191, 207). He uses Charles Sanders Peirce's analysis of the way in which the linguistic sign has to be interpreted as a model for his own definition of irony:

Charles Sanders Peirce, who, with Nietzsche and Saussure, laid the philosophical foundation for modern semiology, stressed the distinction between grammar and rhetoric in his celebrated and so suggestively unfathomable definition of the sign. He insists, as is well known, on the necessary presence of a third element, called the interpretant, within any relationship that the sign entertains with its object. The sign is to be interpreted if we are to understand the idea it is to convey, and this is so because the sign is not the thing but a meaning derived from the thing by a process here called representation that is not simply generative, i.e., dependent on a univocal origin. The interpretation of the sign is not, for Peirce, a meaning but 
another sign; it is a reading, not a decodage, and this reading has, in its turn, to be interpreted into another sign, and so on ad inifinitum. Peirce calls this process by means of which "one sign gives birth to another" pure rhetoric, as distinguished from pure grammar, which postulates the possibility of unproblematic, dyadic meaning, and pure logic, which postulates the possibility of the universal truth of meanings. (Allegories of Reading 9)

The allegorical work is in the same relationship to the past text as is the sign in relation to the object: both are meanings that require interpretation. This interpretation, however, is not a definitive meaning, but anticipates yet further interpretation.

The allegorical nature of The Story of an African Farm has been the focus of commentary by several critics, amongst whom is Patricia Murphy. Although Murphy's definition of allegory may be accused of articulating an essentialist view of the feminine, it is useful for an understanding of allegory's regenerative nature:

Allegory resonates with feminine temporality through the sense of infinity that this emblematic narrative form imparts, since an allegory both enlarges one text to create others and represents a form of eternalizing art .... In Roland Barthes's term, the text becomes a "galaxy of signifiers" instead of "a structure of signifieds."

(90)

Lengthy passages of writing in a traditional allegorical mode are to be found in Schreiner's novel, but my concern here is with the allegorical nature of Perfect Darkness (and its models) as pro-creative adaptation. As an adaptation of Schreiner's novel, the film constitutes a repetition of a past text-of one of the texts of a particular literary tradition. At the same time, in foregrounding its interpretive (rather than appropriational) relationship to The Story of an African Farm, and also its fictional status, the film invites further interpretations of its own visual and auditory imagery.

According to Craig Owens, "in allegorical structure ... one text is read through another, however fragmentary, intermittent, or chaotic their relationship may be; the paradigm for the allegorical work is thus the palimpsest" (69). My film is to be read through the novel, and the novel read through the film-as I have already suggested in the image of the two-sided mirror. Projecting this interface into a new domain, the film opens itself up to interpretation, rather than claiming a union with the novel that would close off other meanings. The allegorical work of art thus admits to its inevitable status as an unfinished work of art. It is perhaps for this reason that allegory, according to Owens, "is consistently attracted to the fragmentary, the imperfect, the incomplete" (70).

The difference, or distance, inherent in allegory is intended to emerge particularly through Perfect Darkness's reevaluation of the novel, set in colonial times, through a postcolonial lens. South Africa in Schreiner's time was of course vastly different from contemporary South Africa, and Perfect Darkness attempts to foreground this difference. The novel loosely centers itself around Lyndall, a white girl growing up in the 1850s in colonial South Africa. It moves from her childhood on a Karroo farm as an abused orphan, to her return from girls' boarding-school, to her 
escape with the stranger mysteriously named "R. R." to the Transvaal, to her lonely, premature death (figured as a sleep-wish) soon after the death of her three-hour-old child (watched over by her transvestite nurse, Gregory Rose). Perfect Darkness transforms the third part of Lyndall's story (from her escape to the Transvaal until her death) into a possible postcolonial equivalent. Jessica-the film's Lyndall figure-has emigrated from South Africa to America five years previous to the film's diegesis; the film traces her developing narcolepsy (a kind of "death in sleep") in America and her strikingly beautiful dreams of South Africa. The only people with whom Jessica has contact are two psychoanalysts, Rose and Gregory (Gregory Rose split into two characters - a white woman and a black man), and the father of her dead child, David (the film's R. R. equivalent), none of whom can fully understand the essence of her illness.

Perfect Darkness thus not only attempts to preserve the pattern of the novel's narrative, but also to reevaluate it through a postcolonial lens in order to highlight what has changed as well as what has not changed in the South African situation. Lyndall and Jessica both flee from their original homes to new places to get "out of the world" (239). In such a way, Perfect Darkness equates Schreiner's African farm with South Africa in general, and Schreiner's Transvaal with America (as a symbolic destination of South African emigration). This is in accordance with Coetzee's reading of the African farm as Schreiner's allegory of colonial South Africa (White Writing 66). Yet it is also an attempt to foreground my own act of producing criticism-as-creation. I chose to adapt The Story of an African Farm because I identified not only with what Schreiner was expressing in the text, but also with the context of the novel's production--an identification that has important creative bearing on Perfect Darkness. As a twenty-one-year-old white woman at the time of making the film (Schreiner was twenty-one when she wrote the novel) attempting to communicate artistically in a foreign context, I found it almost as difficult to anticipate an audience as did Schreiner a century ago. Thus, the film attempts an allegorical response not only to the novel's content, but also to its context of production and other aspects of its "spirit."

The pro-creational adaptation, then, foregrounds the way in which the film constructs a self for and expresses the desire of the adapter; it is, like Wilde's form of criticism, a form of autobiography. It does not deny these functions of criticism, as conventional critical discourse frequently does, but celebrates them. The procreational adaptation claims a kind of freedom for itself, but does not assume dominance over the text. It thus works in an antithetical way not only to conventional critical discourse but also to appropriational adaptation. Appropriational adaptation could be said to undermine the power of both text and film, as each seems to abrogate the expressive force of the other: in borrowing only the narrative from the text, the appropriational adapter submits to reproducing faithfully this aspect of the novel, but at the same time limits the range of meanings that the novel potentially offers. Pro-creational adaptation, on the other hand, in its fidelity to the novel's "spirit"- that is, to the novel's narrative as well as to its other modes of signification-brings to life a multiplicity of meanings, turning the text into a "galaxy of signifiers," empowering both novel and adaptation at the same time. 


\section{Notes}

' Indeed, the equivalence is so conditional that it hardly seems viable to use the very word "grammar" to describe the internal structure of films. For the sake of clarity, however, I shall continue to call it such.

2 Perfect Darkness includes a crucial scene at this mirror, where the faces of the protagonists, Jessica and David, become melded together.

\section{Works Cited}

Braudy, Leo, and Marshall Cohen, eds. Film Theory and Criticism. 5th ed. Oxford: Oxford University Press, 1999.

Chatman, Seymour. "What Novels Can Do That Films Can't (And Vice Versa)." Braudy and Cohen 435-451.

Coetzee, J. M. "Achterberg's 'Ballade van de gasfitter': The Mystery of I and You." Doubling the Point: Essays and Interviews. Ed. David Atwell. Cambridge: Harvard University Press, 1992. 69-90.

—. "Truth in Autobiography." University of Cape Town, Cape Town. 3 Oct. 1984.

- White Writing: On the Culture of Letters in South Africa. New Haven: Yale University Press, 1988.

De Man, Paul. Allegories of Reading. New Haven: Yale University Press, 1979.

-. "The Rhetoric of Temporality." Interpretation: Theory and Practice. Ed. Charles S. Singleton. Baltimore: John Hopkins University Press, 1969. 173-209.

Denman, Kamilla Lee. "Haunted Scenes and Shadowed Texts: Film Adaptations of British Victorian Prose Fiction. Diss. Harvard University, 1996.

Gombrich, E. H. Meditations on a Hobby Horse and Other Essays on the Theory of Art. Oxford: Phaidon Press, 1963.

Jakobson, Roman. Language in Literature. Cambridge: Belknap Press, 1987.

Johnson, Barbara. "Taking Fidelity Philosophically." Difference in Translation. Ed. Joseph F. Graham. Ithaca: Cornell University Press, 1985. 142-148.

Metz, Christian. Film Language: A Semiotics of the Cinema. New York: Oxford University Press, 1974.

Murphy, Patricia. “Timely Interruptions: Unsettling Gender Through Temporality in The Story of an African Farm.” Style 32.1 (Spring 1998): 80-101.

Owens, Craig. "The Allegorical Impulse: Toward a Theory of Postmodernism.” October 12 (Spring 1980): 67-86.

Potter, Sally. Orlando: The Screenplay. London: Faber and Faber, 1994.

Schreiner, Olive. The Story of an African Farm. Middlesex: Penguin Books, 1939.

Sörbom, Göran. Mimesis and Art: Studies in the Origin and Early Development of an Aesthetic Vocabulary. Stockholm: Svenska Bokförlaget, 1966.

Webster's Encyclopedic Unabridged Dictionary. New York: Gramercy Books, 1996.

Wilde, Oscar. "The Critic as Artist: Criticism Itself an Art." The Norton Anthology of English Literature. Ed. M. H. Abrams. 6th ed. 2 vols. New York: Norton, 1993. 2: 1620-1627.

Wollen, Peter. “Godard and Counter Cinema: Vent D'Est." Braudy and Cohen 499-507. 